\title{
Bio-refinery of orange peels waste: A new concept based on integrated green and solvent free extraction processes using ultrasound and microwave techniques to obtain essential oil, polyphenols and pectin
}

\author{
Meryem Boukroufa $^{a}$, Chahrazed Boutekedjiret ${ }^{\mathrm{a}, *}$, Loïc Petigny $^{\mathrm{b}}$, Njara Rakotomanomana ${ }^{\mathrm{b}}$, \\ Farid Chemat ${ }^{\mathrm{b}, *}$ \\ a Laboratoire des Sciences et Techniques de l'Environnement (LSTE), Ecole Nationale Polytechnique, 10 Avenue Hacène Badi, BP 182, El Harrach, 16200 Alger, Algeria \\ ${ }^{\mathrm{b}}$ Avignon University, INRA, UMR408, GREEN Extraction Team, F-84000 Avignon, France
}

\begin{abstract}
A B S T R A C T
In this study, extraction of essential oil, polyphenols and pectin from orange peel has been optimized using microwave and ultrasound technology without adding any solvent but only "in situ" water which was recycled and used as solvent. The essential oil extraction performed by Microwave Hydrodiffusion and Gravity (MHG) was optimized and compared to steam distillation extraction (SD). No significant changes in yield were noticed: $4.22 \pm 0.03 \%$ and $4.16 \pm 0.05 \%$ for MHG and SD, respectively. After extraction of essential oil, residual water of plant obtained after MHG extraction was used as solvent for polyphenols and pectin extraction from MHG residues. Polyphenols extraction was performed by ultrasoundassisted extraction (UAE) and conventional extraction (CE). Response surface methodology (RSM) using central composite designs (CCD) approach was launched to investigate the influence of process variables on the ultrasound-assisted extraction (UAE). The statistical analysis revealed that the optimized conditions of ultrasound power and temperature were $0.956 \mathrm{~W} / \mathrm{cm}^{2}$ and $59.83{ }^{\circ} \mathrm{C}$ giving a polyphenol yield of $50.02 \mathrm{mg} \mathrm{GA} / 100 \mathrm{~g} \mathrm{dm}$. Compared with the conventional extraction (CE), the UAE gave an increase of $30 \%$ in TPC yield. Pectin was extracted by conventional and microwave assisted extraction. This technique gives a maximal yield of $24.2 \%$ for microwave power of $500 \mathrm{~W}$ in only $3 \mathrm{~min}$ whereas conventional extraction gives $18.32 \%$ in 120 min. Combination of microwave, ultrasound and the recycled "in situ" water of citrus peels allow us to obtain high added values compounds in shorter time and managed to make a closed loop using only natural resources provided by the plant which makes the whole process intensified in term of time and energy saving, cleanliness and reduced waste water.
\end{abstract}

\section{Introduction}

Sweet oranges represent by far the most important class of commercial citrus fruits grown in tropical and subtropical regions around the world [1]. Global orange production for 2013/14 is forecast to rise 5 percent from the previous year to 51.8 million metric tons with an orange juice production of 2.0 million metric tons. Citrus by-product resulting from the citrus processing account for about $50 \%$ of their weight [2]. They are composed mainly of skins (flavedo and albedo), pulp, and seeds. From their compositions they represent a source of fat (oleic, linoleic, linolenic, palmitic, stearic, glycerin, and phytosterols), sugars (glucose,

\footnotetext{
* Corresponding authors.

E-mail addresses: chahrazed.boutekedjiret@g.enp.edu.dz (C. Boutekedjiret),
} farid.chemat@univ-avignon.fr (F. Chemat). fructose, sucrose), acids (especially citric and malic acid, tartaric but also, benzoic, oxalic and succinic acids) [3], insoluble carbohydrates (cellulose, pectin) [4], enzymes (pectinesterase, phosphatase, peroxidase), flavonoids (hesperidin, narirutin) [5], essential oils (D-limonene), pectins and pigments (carotenoïds, xanthophylls) [3].

Essential oil extracted from citrus by-product can be used in food as flavoring ingredients in drinks, ice creams and other food products and pharmaceutical industries for its anti inflammatory and antibacterial effect [6]. In addition, substantial quantity of these oil is also used in the preparation of toilet soaps, perfumes, cosmetics and other home care products [7] or as green solvent $[8,9]$.

Phenolic compounds, have gained much attention when consumed regularly. They have been associated with a reduction in the incidence of diseases such as cancer, heart disease, hepatic 
Version définitive du manuscrit publiée dans / Final version of the manuscript published in :

Ultrasonics Sonochemistry (2015), Vol. 24, p. 72-79, DOI: 10.1016/j.ultsonch.2014.11.015

Journal homepage : http://www.elsevier.com/locate/ultson

injury [10,11] and neurodegenerative disorders. They are beneficial against many other health problems such as osteoarthritis [12], and ocular disorders [13], and act as phytoestrogen [14] and antithyroidal compound [15]. Their antioxidant activities and free radical scavenging abilities make them a good source of natural antioxidants mainly in foods to prevent the rancidity and oxidation to replace the use of chemical antioxidants used and which toxicity has already been proven as BHA and BHT [16].

Pectins are one of the compounds which one finds in the citrus. It is found ubiquitously in the epicarp (flavedo), mesocarp (albedo) and endocarp (edible portion) of the lime [17]. The term "pectin" refers to a group of complex polysaccharides that are components of the cell walls of most higher plants [18]. They are characterized by a high content of galacturonic acid (GalA), monomers linked by $\alpha$-links (1-4) and acetylated or partially esterified with methyl groups. Pectin are produced industrially and used as gelling food agent.

With the development of the "Green Chemistry" concept during the last few years, environment-friendly techniques are becoming more and more attractive, therefore, researches aimed at optimizing the most eco-friendly way of extraction. Thus added to the conventional methods of extraction, new methods such as supercritical fluid extraction [19,20], microwave assisted extraction [7,21-25], pulsed-electric field extraction, enzyme-assisted extraction and ultrasound assisted extraction [5,26-31] either for the essential oils and phenolics or pectin reducing the extraction time and therefore the consumed energy are developed.

In this work, a bio-refinery concept was used for extraction of essential oil, polyphenols and pectin from orange peel by integrating a green processes such as microwaves and ultrasounds assisted extraction, giving a sustainable process with high yield of extractions where any hexogen solvent was needed but only endogen water which was recycled and used as solvent.

\section{Materials and methods}

\subsection{Plant material}

In this study, about $100 \mathrm{~kg}$ of orange (Citrus sinensis L. osbeck) peel were collected locally after juice extraction giving an orange peel yield of approximately $20 \%(\mathrm{w} / \mathrm{w}$ ) of the whole fruit. The initial moisture content of orange peel was $59 \%$. Fresh plant material was used in all extractions.

\subsection{Chemicals}

The solvents used were of analytical grade and were purchased from VWR international Darmstadt, Germany. Flavonol glycosides (narirutin, hesperidin) where purchased from Extra Synthese (Genay, France), Folin-Ciocalteu and sodium carbonate $\mathrm{Na}_{2} \mathrm{CO}_{3}$ were purchased from Sigma Aldrich (St. Louis, USA).

\subsection{Protocol treatment}

After a first stage of juice extraction, essential oil extraction of orange peels was carried out by Microwave Hydrodiffusion and Gravity (MHG) or by steam distillation (SD). Then, the "residue" sample of MHG extraction was treated by residual water obtained after MHG process to extract the total phenolic compounds (TPC) and pectin. TPC were extracted using ultrasound-assisted extraction (UAE) and conventional extraction (CE). Solvent extracts were then analyzed and identified by HPLC. Where as a microwave assisted extraction (MAE), and a conventional extraction (CE) were used to recovery pectin. The performed protocol is shown in Fig. 1 .

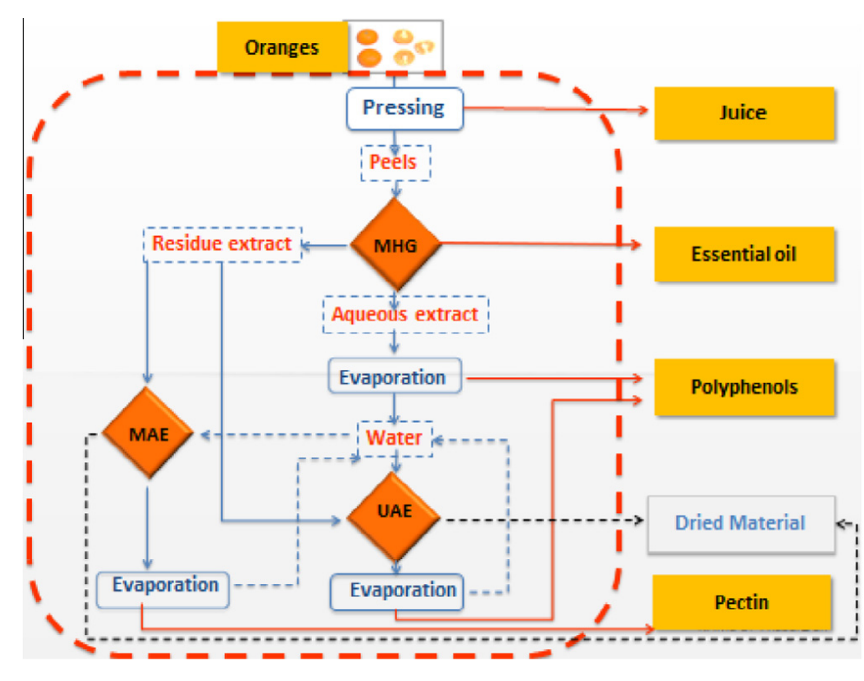

Fig. 1. Protocol treatment of orange peels.

\subsection{Microwave Hydrodiffusion and Gravity (MHG) apparatus and procedure}

MHG extraction has been performed in a Milestone EOS-G microwave laboratory oven (Milestone srl, Bergamo, Italy). This apparatus is a multimode microwave reactor $2.45 \mathrm{GHz}$ with a maximum delivered power of $900 \mathrm{~W}$ variable in $10 \mathrm{~W}$ increments (Fig. 2). In order to determine the optimal extraction conditions in a typical MHG procedure performed at atmospheric pressure, a parametric study was done using $400 \mathrm{~g}$ of fresh plant material collected after juice extraction heated with a variable output power $(200-700 \mathrm{~W})$ for $25 \mathrm{~min}$ without addition of solvent or water.

Microwaves heat the vegetable matrix causing the evaporation of interstitial water and the release of the essential oil. Mixing

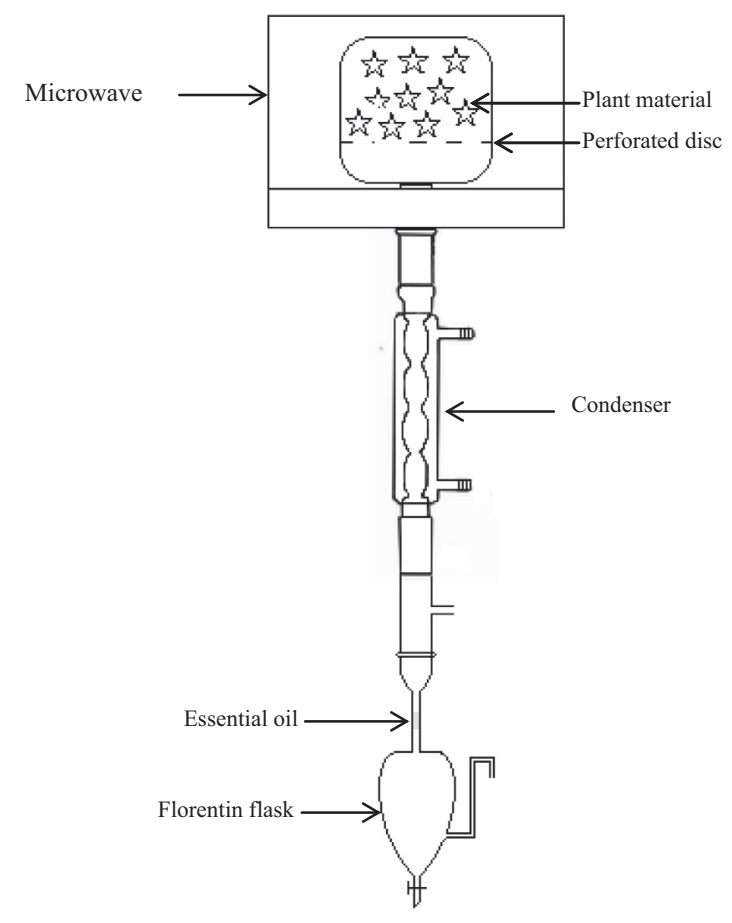

Fig. 2. Microwave Hydrodiffusion and Gravity (MHG) apparatus. 
Version définitive du manuscrit publiée dans / Final version of the manuscript published in :

Ultrasonics Sonochemistry (2015), Vol. 24, p. 72-79, DOI: 10.1016/j.ultsonch.2014.11.015

Journal homepage : http://www.elsevier.com/locate/ultson

essential oil-vapor is then condensed and recovered in a receiving Florentine flask. The essential oil is collected, dried with anhydrous sodium sulfate and stored at $4{ }^{\circ} \mathrm{C}$ until used, while the water recovered is recycled for the polyphenols extraction.

\subsection{Steam distillation (SD) apparatus and procedure}

For a rigorous comparison, the same glassware and same operating conditions have been used for conventional steam distillation. The vapor produced by the steam generator crosses the plant, charged with essential oil and then passes through the condenser to a receiving Florentine flask. The steam distillation was performed for an optimal steam flow of $16 \mathrm{~g} / \mathrm{min}$ previously determined by a parametric study. The essential oil is collected, dried with anhydrous sodium sulfate and stored at $4{ }^{\circ} \mathrm{C}$ until used.

\subsection{Ultrasound assisted extraction (UAE)}

Ultrasound-assisted extractions (UAE) were performed in an ultrasonic extraction reactor PEX1 (R.E.U.S., Contes, France) with $14 \times 10 \mathrm{~cm}$ internal dimensions and maximal capacity of $1 \mathrm{~L}$, equipped with a transducer at the base of jug operating at a frequency of $25 \mathrm{kHz}$ with maximum input power of $150 \mathrm{~W}$. The extraction temperature was controlled using the double layered mantle by cooling/heating systems (Fig. 3).

In order to take account of the power fraction converted to heat dissipated in the medium, calorimetric measurements were carried out to evaluate the real ultrasounds power. The values of power were then calculated using Eq. (1) [32].

$P=m C_{p} \frac{d T}{d t}$

where $m$ is the mass of solvent $(\mathrm{g}), C_{p}$ the heat capacity of the solvent at constant pressure $\left(\mathrm{J} \mathrm{g}^{-1} \mathrm{~K}^{-1}\right)$, and $d T / d t$ is the temperature variation according to time.

The ultrasonic power was then expressed as ultrasonic intensity (UI), calculated using Eq. (2) [32].

$\mathrm{UI}=\frac{4 P}{\pi D^{2}}$

where $\mathrm{UI}$ is the ultrasonic intensity $\left(\mathrm{W} \mathrm{cm}^{-2}\right), P$ the ultrasound power (W) calculated by the Eq. (1), and $D$ the internal diameter $(\mathrm{cm})$ of the ultrasound reactor.

\subsection{Extraction procedure of total phenolic compounds (TPC)}

In the first, TPC were extracted from residual water of plant obtained after MHG extraction, and then the recycled residual water of plant obtained was used for TPC extraction from MHG residues using ultrasound-assisted extraction (UAE) and conventional extraction (CE). An optimization by response surface methodology (RSM) was done for the UAE by varying the operating parameters namely temperature and ultrasound power. Conventional extraction (CE) of polyphenols was then performed using the optimum temperature obtained by RSM study. The extraction time and the solid-liquid ratio previously determined by a preliminary study were fixed at $30 \mathrm{~min}$ and 1/10. The particle size considered as one of the important factors that can affect the efficiency of polyphenol extraction from orange peels, was fixed at $2 \mathrm{~cm}^{2}$ in accordance with previous studies [5].

\subsection{Experimental design}

To investigate the performance of UAE of total phenolic compounds, response surface methodology (RSM) was employed. Central Composite Design (CCD) is used to achieve maximal information about the process from a minimal number of possible experiments. The multivariate study allows the identification of interaction between variables and provides a complete exploration of the experimental studied domain. The type of CCD used in this study was Central composite face-centered (CCF) experimental design to determine the optimal conditions. The application of a CCF design is a convenient way to optimize a process with three levels $(-1,0$ and +1$)$ for each factor [33,34]. In this design, the star points are at the center of each face of the factorial space, thus $\pm \alpha= \pm 1$. This design is needed to evaluate the simple and quadratic effects and interactions of the operational parameters, namely temperature $T\left({ }^{\circ} \mathrm{C}\right)(\mathrm{A})$ and ultrasound power expressed as the ultrasonic intensity $\mathrm{UI}\left(\mathrm{W} \mathrm{cm}^{-2}\right)(\mathrm{B})$. The limit values of the ultrasonic intensity were chosen as function of limitations of ultrasonic apparatus (minimum and maximum power available in the device). Temperatures of extraction for polyphenols were fixed between $20^{\circ} \mathrm{C}$ and $60{ }^{\circ} \mathrm{C}$. This latter was selected to check if there is degradation of the polyphenols. The coded levels and the natural values of the factors are shown in Table 1. A total of 12 different combinations including four replicates of center point, each designated by the coded value 0 , were chosen in random order accord-

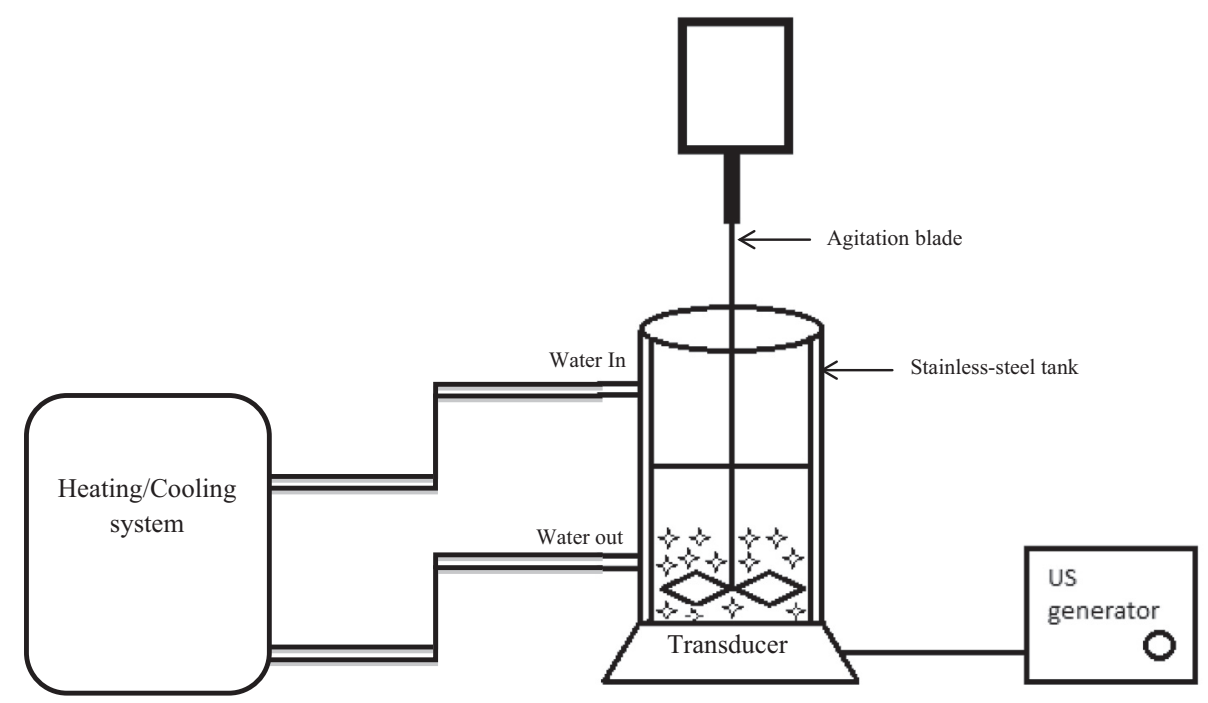

Fig. 3. Ultrasound Assisted Extraction reactor. 
Version définitive du manuscrit publiée dans / Final version of the manuscript published in :

Ultrasonics Sonochemistry (2015), Vol. 24, p. 72-79, DOI: 10.1016/j.ultsonch.2014.11.015

Journal homepage : http://www.elsevier.com/locate/ultson

Table 1

Central composite design with their observed response.

\begin{tabular}{|c|c|c|c|c|c|}
\hline \multirow[t]{2}{*}{ Run } & \multicolumn{2}{|c|}{ Coded variables } & \multicolumn{2}{|l|}{ Decoded variables } & \multirow{2}{*}{$\begin{array}{l}\text { Response } \\
\mathrm{Y}_{\mathrm{TPC}}(\mathrm{mg} \mathrm{GA} / 100 \mathrm{~g} \mathrm{dm})\end{array}$} \\
\hline & A & B & Temperature $\left({ }^{\circ} \mathrm{C}\right)$ & $\mathrm{UI}\left(\mathrm{W} / \mathrm{cm}^{2}\right)^{\mathrm{a}}$ & \\
\hline 1 & 0 & 0 & 40.0 & 0.575 & 44.17 \\
\hline 2 & 0 & 0 & 40.0 & 0.575 & 43.83 \\
\hline 3 & +1 & 0 & 60.0 & 0.575 & 45.85 \\
\hline 4 & -1 & -1 & 20.0 & 0.191 & 32.22 \\
\hline 5 & 0 & 0 & 40.0 & 0.575 & 43.83 \\
\hline 6 & 0 & -1 & 40.0 & 0.191 & 42.26 \\
\hline 7 & -1 & +1 & 20.0 & 0.958 & 42.07 \\
\hline 8 & -1 & 0 & 20.0 & 0.575 & 35.41 \\
\hline 9 & +1 & +1 & 60.0 & 0.958 & 49.94 \\
\hline 10 & 0 & 0 & 40.0 & 0.575 & 44.36 \\
\hline 11 & +1 & -1 & 60.0 & 0.191 & 39.47 \\
\hline 12 & 0 & +1 & 40.0 & 0.958 & 48.80 \\
\hline
\end{tabular}

Bold values represent the optimum operating conditions and the corresponding Yield in function of TPC.

a UI: ultrasonic intensity.

ing to a CCF configuration for two factors. The selected optimization parameter was TPC yield ( $\mathrm{Y}_{\mathrm{TPC}}$ ) after $30 \mathrm{~min}$ expressed as mg Gallic Acid/100 g dry matter. The experimental design used were constructed and the experimental results processed by using the software STATGRAPHICS PLUS (Version 5.1, Statistical Graphics Corporation, Rockville, USA, 2000).

\subsection{Total phenolic content (TPC)}

The total phenolic amount was measured by Folin-Ciocalteu method, based on a colorimetric oxidation/reduction reaction of phenol. $20 \mu \mathrm{L}$ of extract were mixed with $2 \mathrm{~mL}$ of Folin-Ciocalteu reagent, $1 \mathrm{~mL}$ of sodium carbonate $\mathrm{Na}_{2} \mathrm{CO}_{3}$ (7\%) was then added. The sample was allowed to stand in the dark for $30 \mathrm{~min}$ at room temperature until measuring their absorbance at $760 \mathrm{~nm}$. TPC yield was expressed as mg of Gallic Acid/100 g dry matter (dm).

\subsection{HPLC analysis}

HPLC analyses were performed using a Waters (Milford, MA) HPLC system consisting of a Waters 600E pump, a Waters 717 autosampler, a Waters 2996 photodiode array detector. The HPLC pumps, autosampler, column temperature, and diode array system were monitored and controlled by using Waters Empower 2 Chromatography Data software program. The wavelength used for the quantification of the flavanone glycosides with the diode detector was $280 \mathrm{~nm}$. The chromatographic separation was carried out on a Purospher Star RP-18 end-capped column $(250 \mathrm{~mm} \times 4 \mathrm{~mm}$ I.D.; $5 \mu \mathrm{m}$ particle size from VWR), with a RP18 guard column ( $4 \mathrm{~mm} \times 4 \mathrm{~mm}$ I.D.; $5 \mu \mathrm{m}$ particle size also from VWR). The endcapped column and guard column were held at $37^{\circ} \mathrm{C}$ and the flow rate was set at $1 \mathrm{~mL} / \mathrm{min}$. The mobile phase consisted of two solvents: $0.5 \%$ acetic acid (A) and $100 \%$ acetonitrile (B). The solvent gradient in volume ratios was as follows: $10-30 \%$ B over $20 \mathrm{~min}$. The solvent gradient was increased to $35 \% \mathrm{~B}$ at $25 \mathrm{~min}$ and it was maintained at 35\% B for 5 min. The injection volume was $20 \mu \mathrm{L}$. Analyses were performed at least three times and only mean values were reported. Quantification was carried out by using the external standard method and the final concentrations were calculated in $\mathrm{mg} / 100 \mathrm{~g}$ dry matter $(\mathrm{dm})$.

\subsection{Pectin extraction procedure}

$5 \mathrm{~g}$ of dried and milled MHG residue of citrus peel was added to $150 \mathrm{~mL}$ of MHG recycled water in a glass vessel. After adjusting the pH to 2 with $\mathrm{HNO}_{3}(0.1 \mathrm{~N})$ as extracting agent, the mixture was placed in a microwave oven, and heated with different powers:
200, 300, 400 and $500 \mathrm{~W}$. Then the mixture was cooled and filtered before adjusting $\mathrm{pH}$ to 4.5 with $\mathrm{NaOH}(0.1 \mathrm{~N})$. The filtrate was evaporated and coagulated using a volume of ethanol equal to twice the filtrate and left for $24 \mathrm{~h}$. The coagulated pectin was then separated by filtration and dried at $50 \mathrm{C}$.

Conventional extraction of pectin was performed in the same operating conditions and was heated using a water bath for $2 \mathrm{~h}$.

The pectin yield was expressed as a weight of dried pectin/100 $\mathrm{g}$ of dried orange peel.

\section{Results and discussion}

\subsection{Preliminary study of essential oil extraction}

To ensure that the essential oil is quickly and completely extracted using MHG process, the choice of an appropriate microwave irradiation power is important. Indeed, low powers do not allow recovering the totality of essential oil, whereas high powers can destroy the vegetable matter.

The results of the parametric study of the extraction of the orange peels essential oil by MHG shown in Fig. 4, revealed an optimal yield of $4.22 \pm 0.03 \%$ for power of $500 \mathrm{~W}$. This power was chosen as an optimum since it allows in only $15 \mathrm{~min}$ extracting completely the essential oil.

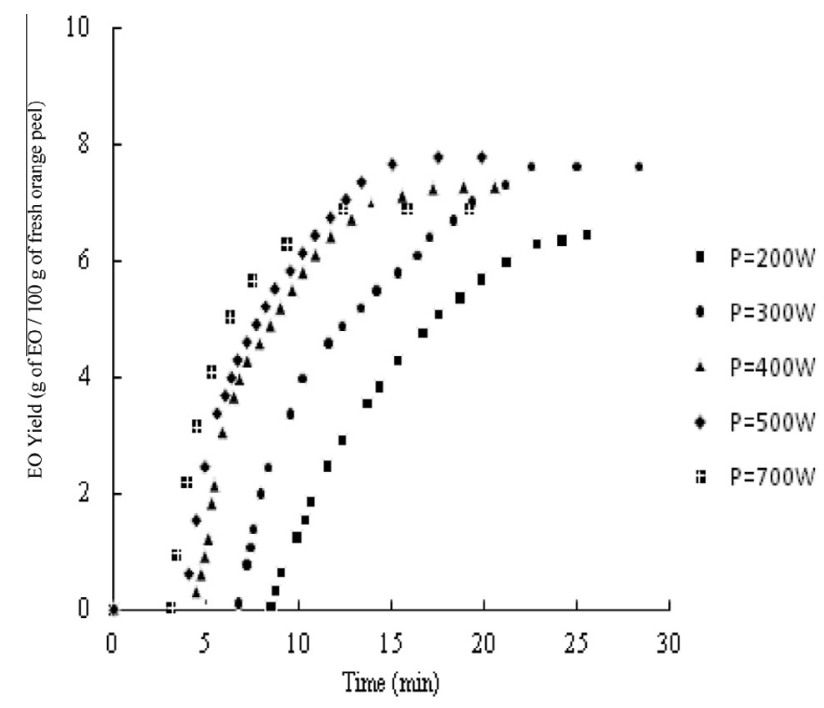

Fig. 4. Yield ( $\mathrm{g}$ of EO/100 $\mathrm{g}$ of fresh orange peel) profiles as function of power for MHG extraction of essential oil from orange peels. 
Version définitive du manuscrit publiée dans / Final version of the manuscript published in :

Ultrasonics Sonochemistry (2015), Vol. 24, p. 72-79, DOI: 10.1016/j.ultsonch.2014.11.015

Journal homepage : http://www.elsevier.com/locate/ultson

\subsection{Essential oil yield and extraction time}

Essential oil yields obtained by MHG an SD processes are comparable: $4.22 \pm 0.03 \%$ for MHG against $4.16 \pm 0.05 \%$ for SD, a difference is only observed in the extraction time. Indeed, $15 \mathrm{~min}$ of extraction with this process are enough to extract totality from oil whereas it takes 240 min with SD, which is the one of the reference methods in essential oil extraction. Therefore MHG is clearly faster than conventional SD with an undeniable gain of time of more than $93 \%$. Advantages in terms of reducing time due to microwaves were also reported by other studies such as PérinoIssartier et al. for lavender essential oil (15 min with MHG Vs 120 min with SD) [35], Sahraoui et al. for essential oil extraction using microwave steam distillation (MSD) who saw the extraction time switch from $3 \mathrm{~h}$ for SD to 6 min for MSD, for Citrus essential oil [7], 6 min with MSD Vs 40 min with SD for lavender essential oil [24]; and Farhat et al. for essential oil extraction from orange peel with microwave steam diffusion (12 min Vs 40 min for steam diffusion) [22].

As shown in Fig. 5, the extraction kinetics of essential oil for both MHG and SD processes are the same extraction profile characterized by three distinct phases. However, extraction speeds are different depending on the process used. Step 0 representing the heating phase from room temperature to $100^{\circ} \mathrm{C}$, is faster for MHG with 4 min against $40 \mathrm{~min}$ for SD. The first step (Step 1) is represented by a rapid increase in the yield which characterizes the extraction of the oil located at the surface of vegetable particles. In this step approximately $76 \%$ of the yield were obtained into $4 \mathrm{~min}$ for MHG, and $61.53 \%$ into $37 \mathrm{~min}$ for SD. This phase is fol-
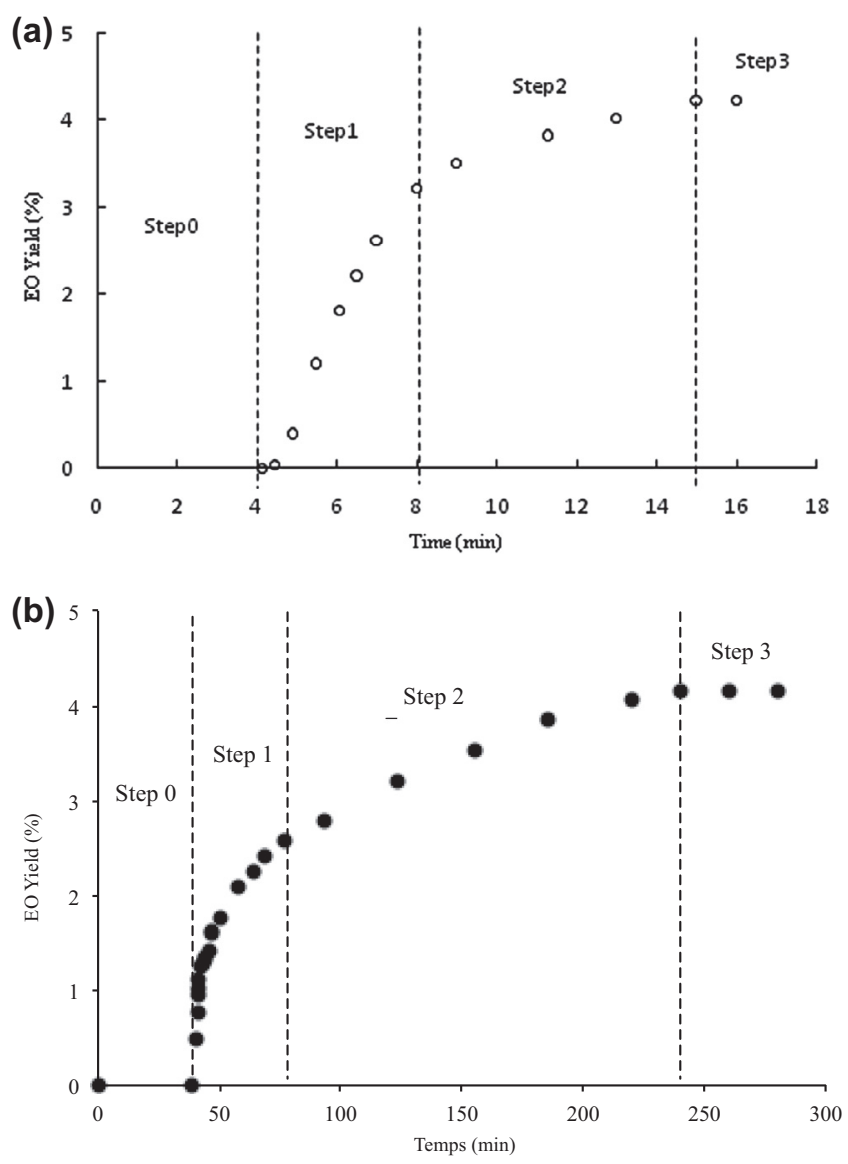

Fig. 5. Comparison between MHG (a) and SD (b) extraction of essential oil from orange peels. lowed by a second increasing line (Step 2) realized into 7 min for MHG and $163 \mathrm{~min}$ for SD. This phase corresponds to the intern diffusion of the essential oil from the midst of the particles towards the external medium involved by the heating of the interstitial water of the plant. The oil amount extracted represents $24 \%$ for MHG and 38.46\% for SD of the global yield. The end of the extraction process marked by a horizontal line corresponds to Step 3.

\subsection{Statistical analysis for UAE extraction of TPC}

The coded and decoded (natural) values of independent variables and TPC yields obtained for different trials of the experimental design protocol are shown in Table 1 . These results were analyzed statistically through Statgraphics software in order to obtain the optimal UAE parameters.

The importance and the statistical significance of the effects (linear, quadratic and interactions between variables) of all variables in the model are illustrated by the standardized Pareto Chart diagram (Fig. 6). Positive and negative effects of the factors in the response variables are represented by horizontals bars and the vertical line tests the significance of the effects at the $95 \%$ confidence level. From this figure, it can be deduced that there are three significant effects. Linear effect of ultrasonic intensity (UI) is the most affecting factor, followed closely by that of the temperature $(T)$ and the quadratic effect of the temperature.

The quantitative effects of process variables and their interactions on the measured response can be described by a mathematical relationship obtained with statistical software Statgraphics. The values of the coefficients of UI and $T$ were related to the effect of these variables on the TPC yield. A positive value represented an effect that favors the operation, while a negative value indicated an antagonistic effect. The second-order polynomial equation of the response surface obtained is as follows:

$$
\begin{aligned}
\mathrm{Y}_{\mathrm{TPC}}= & 15.4330+1.0036 T+3.9214 \mathrm{UI}-0.01003 T^{2} \\
& +0.0202 T \mathrm{UI}+6.0429 \mathrm{UI}^{2}
\end{aligned}
$$

ANOVA gave a coefficient of determination $\left(R^{2}\right)$ of $97.05 \%$ for TPC determination, which indicate a close agreement between experiment and predictive values.

Taking into account only a significant influence of the parameters one can assume that:

$\mathrm{Y}_{\mathrm{TPC}}=15.4330+1.0036 \mathrm{~T}+3.9214 \mathrm{UI}-0.01003 \mathrm{~T}^{2}$

By analyzing the surface plots obtained for TPC yield as a function of temperature and ultrasonic intensity (Fig. 7), one can see that the optimum values for the two parameters that result in the highest extraction yield of TPC can be found around the higher level values of both factors in the experimental domain. In fact, the statistical software defined a temperature of $59.83^{\circ} \mathrm{C}$ and an ultrasonic intensity of $0.956 \mathrm{~W} \mathrm{~cm}^{-2}$ as maximizing the TPC yield (optimum calculated yield $50.02 \mathrm{mg} \mathrm{GA} / 100 \mathrm{~g} \mathrm{dm}$ ).

Comparing these results with those obtained under the experimental conditions closer to the optimum (run 9: $60^{\circ} \mathrm{C}$ and $0.958 \mathrm{~W} / \mathrm{cm}^{2}, \mathrm{Y}_{\mathrm{TPC}}=49.94 \mathrm{mg} \mathrm{GA} / 100 \mathrm{~g} \mathrm{dm}$; see Table 1 ), one can see that the values predicted by the model and the experimental values are very close.

\subsection{Comparison between UAE and CE of TPC}

In order to evaluate the impact of ultrasound-assisted extraction on TPC yield, a comparison study was carried out between ultrasound and conventional extractions in optimized conditions obtained from the response surface methodology $\left(T=60^{\circ} \mathrm{C}\right.$, $\left.\mathrm{UI}=0.958 \mathrm{~W} / \mathrm{cm}^{2}\right)$. 
Version définitive du manuscrit publiée dans / Final version of the manuscript published in :

Ultrasonics Sonochemistry (2015), Vol. 24, p. 72-79, DOI: 10.1016/j.ultsonch.2014.11.015

Journal homepage : http://www.elsevier.com/locate/ultson

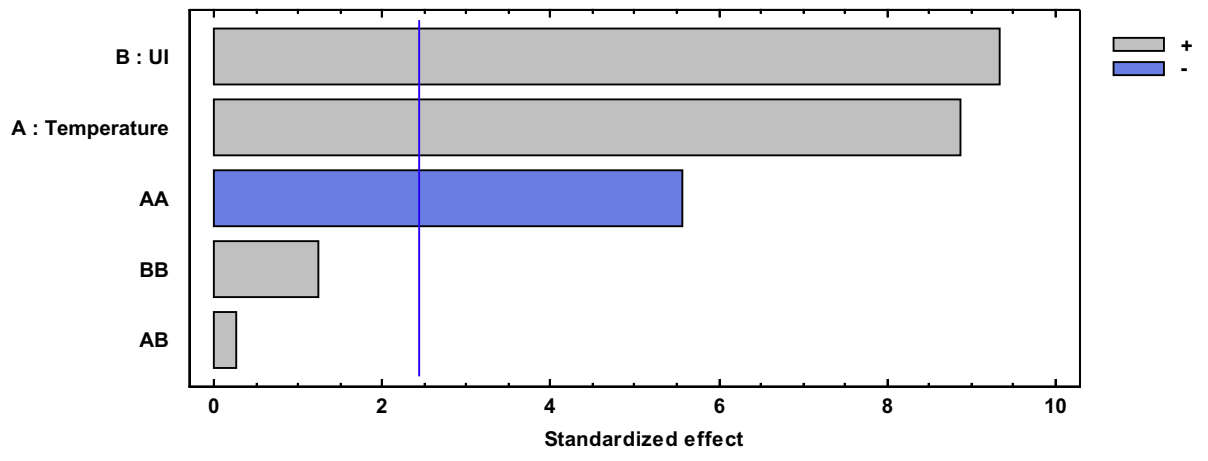

Fig. 6. Standardized Pareto Chart for TPC yield.

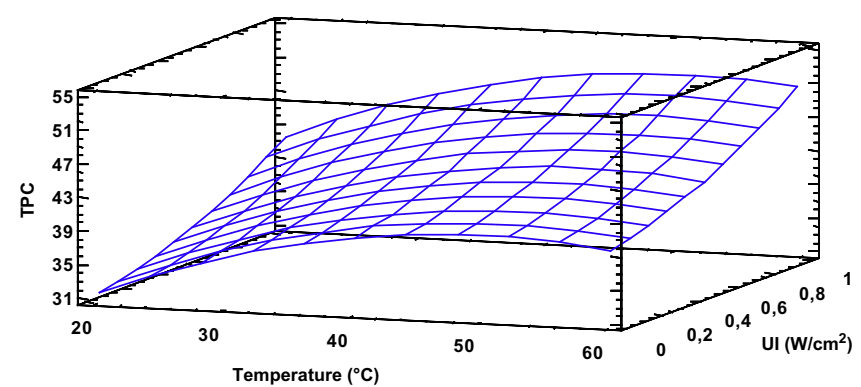

Fig. 7. Response Surface Plots for TPC yield depending on the temperature and the ultrasound power.

The comparison of kinetic of UAE and CE extraction presented on Fig. 8 shows a clear improvement of UAE extraction. Indeed, we can see that ultrasound-assisted extraction involve an increase of $30 \%$ in TPC yield (41.23 and $58.55 \mathrm{mg}$ of Gallic acid equivalent per100 $\mathrm{g}$ of dry weight for conventional and ultrasound-assisted extraction, respectively). This intensification is due to a mechanical, cavitations and thermal effect resulting from disruption of cell walls, practical size reduction and enhanced mass transfer across cell-membrane $[5,36,37]$. The same observations were reported by Pingret et al. for polyphenols extraction from apple pomace [32]. Herrera and Pinelo reported also an increasing of the yield extraction in a shorter time and less degradation of polyphenols than methods as solid-liquid subcritical water and microwave assisted extraction $[38,39]$.

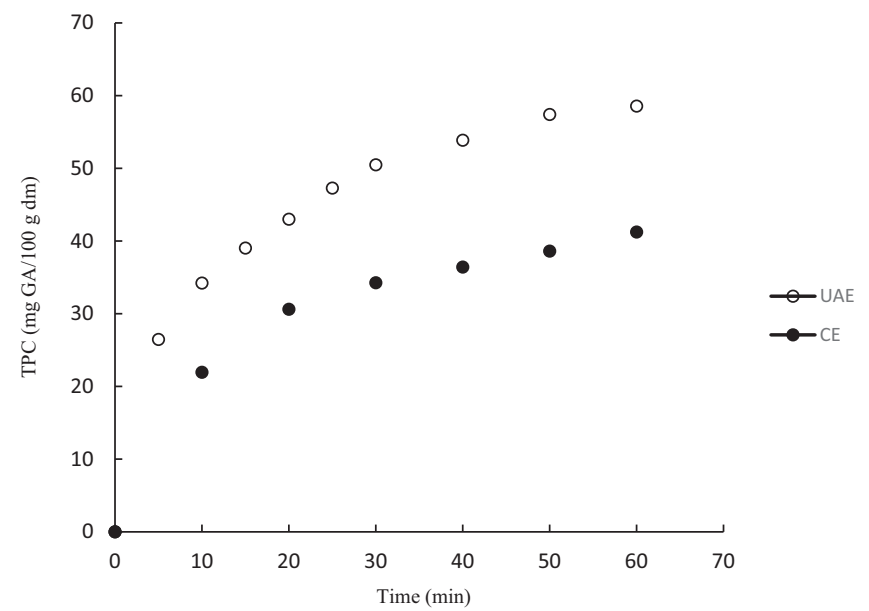

Fig. 8. Comparison between conventional (CE) and ultrasound assisted extraction (UAE).
These results are supported by HPLC analysis, both UAE and CE showed that the main flavanone glycosides found in orange are narirutin and hesperidin with remarkable difference in concentration of both compounds: $0.11 \mathrm{mg}$ narirutin $/ \mathrm{g} \mathrm{dm}$ for $\mathrm{CE}$ and $0.55 \mathrm{mg}$ narirutin/g dm for UAE; $1.18 \mathrm{mg}$ hesperidin $/ \mathrm{g} \mathrm{dm}$ for CE and $1.45 \mathrm{mg}$ hesperidin/g dm for UAE. Compared to conventional extraction, UAE allowed a better extraction of these flavones glycoside. In addition, HPLC analysis of the MHG aqueous extract of orange peels shows only traces amount, below quantification levels of narirutin and hesperidin.

\subsection{Pectin extraction}

The experimental data showing the effects of microwave heating on the pectin yield has been presented in Table 2 and Fig. 9. We can see that a microwave power has a small effect on pectin yield, but a difference is observed on the extraction time. The maximal yield of $24.2 \%$ was obtained for microwave power of $500 \mathrm{~W}$ in only an extraction time of $3 \mathrm{~min}$. Comparing to the conventional pectin extraction, the yield obtained is lower (18.32\%) for a longer extraction time of $2 \mathrm{~h}$. This phenomenon is related to the microwave

Table 2

Yield and time extraction of pectin from orange peel using conventional and microwave assisted extraction.

\begin{tabular}{llllll}
\hline & CE & \multicolumn{4}{l}{ Microwave power (W) } \\
\cline { 3 - 6 } & & 200 & 300 & 400 & 500 \\
\hline Y $_{\text {Pectin }}(\%)$ & 18.32 & 22.2 & 23.01 & 23.94 & 24.2 \\
Time (min) & 120 & 6 & 5 & 4 & 3 \\
\hline
\end{tabular}

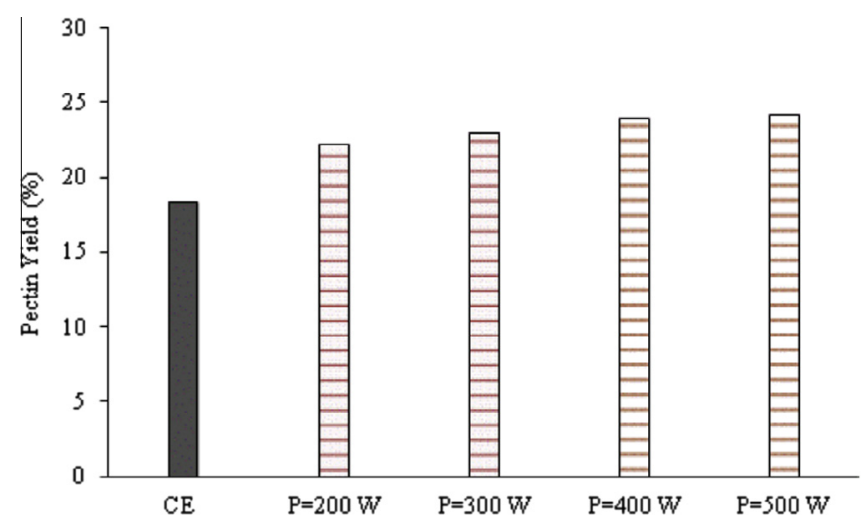

Fig. 9. Comparison between conventional (CE) and microwave assisted extraction (MAE) of pectin from orange peels. 
Table 3

The amounts of products obtained from $100 \mathrm{~kg}$ of orange fruit.

\begin{tabular}{|c|c|c|c|c|c|c|c|c|}
\hline \multirow{2}{*}{$\begin{array}{l}\text { Extract } \\
\text { Process }\end{array}$} & \multicolumn{2}{|c|}{ Essential oil (g) } & \multicolumn{3}{|c|}{ TPC ( $g$ eq GA) } & \multicolumn{2}{|c|}{ Pectin $(\mathrm{kg})$} & \multirow{2}{*}{$\begin{array}{l}\text { Juice }(\mathrm{kg}) \\
\text { Pressure }\end{array}$} \\
\hline & MHG & SD & UAE & CE & MHG & MAE & $\mathrm{CE}$ & \\
\hline $20 \mathrm{~kg}$ peels & 346 & 342 & 11.71 & 8.25 & 0.016 & 4.83 & 3.66 & 43.3 \\
\hline
\end{tabular}

effect on the plant material. Indeed, microwaves distend the plant cells and lead to rupture the cell wall matrix and the skin tissues which lead to increase interaction between extracting agent and the plant material. The same results were noticed by several authors as Bagherian et al. in the study on the comparison between conventional, microwave and ultrasound-assisted methods for extraction of pectin from grapefruit [4]. These authors showed that pectin yield, galacturonic acid content, and degree of esterification increased with an increase in microwave power. Prakash Maran et al. also showed that the extraction assisted by microwaves improved the pectin yield from orange peel, a maximum yield of $19.24 \%$ was obtained for a microwave power of $422 \mathrm{~W}$ and $\mathrm{pH}$ of $1.4[40]$.

\subsection{The amounts of products obtained from $100 \mathrm{~kg}$ of orange fruit}

After juice, essential oil, polyphenols and pectin extraction from orange, we summarize in Table 3 . the amounts of products obtained from $100 \mathrm{~kg}$ of orange fruit. As we can observe, the integration of innovative technology made it possible to improve the yields of extracts, and to decrease the processing times and consequently the energy consumption. From $100 \mathrm{Kg}$ of citrus, we obtained $346 \mathrm{~g}$ of essential oil, $11.71 \mathrm{~g}$ eq Gallic Acid of polyphenols, $4.83 \mathrm{~kg}$ of pectin and $43.3 \mathrm{~kg}$ of orange juice without adding any solvent.

\section{Conclusion}

In this study a new concept based on the bio-refinery of orange peel waste was developed. Combination of microwave, ultrasound and the recycled "in situ" water of citrus peels let us to obtain high added values compounds in shorter time and managed to make a closed loop using only the resources provided by the plant which is better in term of time and energy saving, cleanliness and reduced waste water. This procedure involves an environmentally green approach, and can be generalized to other by-products.

\section{References}

[1] B. Sayinci, S. Ercisli, I. Ozturk, Z. Eryilmaz, B. Demir, Determination of size and shape in the 'Moro' blood orange and 'Valencia' sweet orange cultivar and its mutants using image processing, Not. Bot. Horti Agrobot. Cluj Napoca 40 (2012).

[2] T. Allaf, V. Tomao, K. Ruiz, F. Chemat, Instant controlled pressure drop technology and ultrasound assisted extraction for sequential extraction of essential oil and antioxidants, Ultrason. Sonochem. 20 (2013) 239-246.

[3] V. Bampidis, P. Robinson, Citrus by-products as ruminant feeds: a review, Anim. Feed Sci. Technol. 128 (2006) 175-217.

[4] H. Bagherian, F. Zokaee Ashtiani, A. Fouladitajar, M. Mohtashamy, Comparisons between conventional, microwave-and ultrasound-assisted methods for extraction of pectin from grapefruit, Chem. Eng. Process. 50 (2011) 1237-1243.

[5] M.K. Khan, M. Abert-Vian, A.-S. Fabiano-Tixier, O. Dangles, F. Chemat, Ultrasound-assisted extraction of polyphenols (flavanone glycosides) from orange (Citrus sinensis L.) peel, Food Chem. 119 (2010) 851-858.

[6] M. Virot, V. Tomao, C. Ginies, F. Visinoni, F. Chemat, Green procedure with a green solvent for fats and oils' determination: microwave-integrated Soxhlet using limonene followed by microwave Clevenger distillation, J. Chromatogr. A 1196 (2008) 147-152.
[7] N. Sahraoui, M.A. Vian, M. El Maataoui, C. Boutekedjiret, F. Chemat, Valorization of citrus by-products using Microwave Steam Distillation (MSD), Innov. Food Sci. Emerg. Technol. 12 (2011) 163-170.

[8] S. Bertouche, V. Tomao, K. Ruiz, A. Hellal, C. Boutekedjiret, F. Chemat, First approach on moisture determination in food products using alpha-pinene as an alternative solvent for Dean-Stark distillation, Food Chem. 134 (2012) 602605.

[9] S. Veillet, V. Tomao, K. Ruiz, F. Chemat, Green procedure using limonene in the Dean-Stark apparatus for moisture determination in food products, Anal. Chim. Acta 674 (2010) 49-52.

[10] S. Raj, K. Gothandam, Hepatoprotective effect of polyphenols rich methanolic extract of Amorphophallus commutatus var. wayanadensis against $\mathrm{CCl}_{4}$ induced When consumed regularly by humans, flavonoids have been associated with a reduction in the incidence of diseases such as cancer and heart disease swiss albino mice, Food Chem. Toxicol. 67 (2014) 105-112.

[11] I. Ignat, I. Volf, V.I. Popa, A critical review of methods for characterisation of polyphenolic compounds in fruits and vegetables, Food Chem. 126 (2011) 1821-1835.

[12] R. Farid, Z. Rezaieyazdi, Z. Mirfeizi, M.R. Hatef, M. Mirheidari, H. Mansouri, H. Esmaelli, G. Bentley, Y. Lu, Y. Foo, Oral intake of purple passion fruit peel extract reduces pain and stiffness and improves physical function in adult patients with knee osteoarthritis, Nutr. Res. 30 (2010) 601-606.

[13] S. Majumdar, R. Srirangam, Potential of the bioflavonoids in the prevention/ treatment of ocular disorders, J. Pharm. Pharmacol. 62 (2010) 951-965.

[14] W. Cherdshewasart, S. Subtang, W. Dahlan, Major isoflavonoid contents of the phytoestrogen rich-herb Pueraria mirifica in comparison with Pueraria lobata, J. Pharm. Biomed. Anal. 43 (2007) 428-434.

[15] A.K. Chandra, N. De, Goitrogenic/antithyroidal potential of green tea extract in relation to catechin in rats, Food Chem. Toxicol. 48 (2010) 2304-2311.

[16] T. Ak, İ. Gülçin, Antioxidant and radical scavenging properties of curcumin, Chem. Biol. Interact. 174 (2008) 27-37.

[17] M.L. Fishman, H.K. Chau, P.D. Hoagland, A.T. Hotchkiss, Microwave-assisted extraction of lime pectin, Food Hydrocolloids 20 (2006) 1170-1177.

[18] M. Masmoudi, S. Besbes, F. Abbes, C. Robert, M. Paquot, C. Blecker, H. Attia, Pectin extraction from lemon by-product with acidified date juice: effect of extraction conditions on chemical composition of pectins, Food Bioprocess Technol. 5 (2012) 687-695.

[19] L. Xu, X. Zhan, Z. Zeng, R. Chen, H. Li, T. Xie, S. Wang, Recent advances on supercritical fluid extraction of essential oils, Afr. J. Pharm. Pharmacol. 5 (2011) 1196-1211.

[20] K. Ghafoor, F. Al-Juhaimi, Y. Choi, Supercritical fluid extraction of phenolic compounds and antioxidants from grape (Vitis labrusca B.) seeds, Plant Foods Hum. Nutr. 67 (2012) 407

[21] F. Benkaci-Ali, R. Akloul, A. Boukenouche, E.D. Pauw, Chemical composition of the essential oil of Nigella sativa seeds extracted by microwave steam distillation, J. Essent. Oil Bear. Plants 16 (2013) 781-794.

[22] A. Farhat, A.-S. Fabiano-Tixier, M.E. Maataoui, J.-F. Maingonnat, M. Romdhane F. Chemat, Microwave steam diffusion for extraction of essential oil from orange peel: kinetic data, extract's global yield and mechanism, Food Chem. 125 (2011) 255-261.

[23] A. Filly, X. Fernandez, M. Minuti, F. Visinoni, G. Cravotto, F. Chemat, Solventfree microwave extraction of essential oil from aromatic herbs: from laboratory to pilot and industrial scale, Food Chem. 150 (2014) 193-198.

[24] N. Sahraoui, M.A. Vian, I. Bornard, C. Boutekedjiret, F. Chemat, Improved microwave steam distillation apparatus for isolation of essential oils: comparison with conventional steam distillation, J. Chromatogr. A 1210 (2008) 229-233.

[25] H.B. Yu, L.F. Ding, Z. Wang, L.X. Shi, Study on extraction of polyphenol from grape peel microwave-assisted activity, Adv. Mater. Res. 864 (2014) 520525.

[26] S. Both, F. Chemat, J. Strube, Extraction of polyphenols from black teaconventional and ultrasound assisted extraction, Ultrason. Sonochem. (2013).

[27] L. Galvan d'Alessandro, K. Kriaa, I. Nikov, K. Dimitrov, Ultrasound assisted extraction of polyphenols from black chokeberry, Sep. Purif. Technol. 93 (2012) 42-47.

[28] G.B. Gonzales, G. Smagghe, K. Raes, J. Van Camp, Combined alkaline hydrolysis and ultrasound-assisted extraction for the release of nonextractable phenolics from cauliflower (Brassica oleracea var. botrytis) waste, J. Agric. Food Chem. (2014).

[29] D. Horžić, A.R. Jambrak, A. Belščak-Cvitanović, D. Komes, V. Lelas, Comparison of conventional and ultrasound assisted extraction techniques of yellow tea and bioactive composition of obtained extracts, Food Bioprocess Technol. 5 (2012) 2858-2870. 
Version définitive du manuscrit publiée dans / Final version of the manuscript published in :

Ultrasonics Sonochemistry (2015), Vol. 24, p. 72-79, DOI: 10.1016/j.ultsonch.2014.11.015

Journal homepage : http://www.elsevier.com/locate/ultson

[30] D.B. Muñiz-Márquez, G.C. Martínez-Ávila, J.E. Wong-Paz, R. Belmares-Cerda, R. Rodríguez-Herrera, C.N. Aguilar, Ultrasound-assisted extraction of phenolic compounds from Laurus nobilis L. and their antioxidant activity, Ultrason. Sonochem. 20 (2013) 1149-1154.

[31] Y. Tao, D. Wu, Q.-A. Zhang, D.-W. Sun, Ultrasound-assisted extraction of phenolics from wine lees: modeling, optimization and stability of extracts during storage, Ultrason. Sonochem. 21 (2014) 706-715.

[32] D. Pingret, A.-S. Fabiano-Tixier, C.L. Bourvellec, C.M. Renard, F. Chemat, Lab and pilot-scale ultrasound-assisted water extraction of polyphenols from apple pomace, J. Food Eng. 111 (2012) 73-81.

[33] J. Goupy, Pratiquer les plans d'expériences, Dunod, 2005.

[34] P. Maurice, Les plans d'expériences par la méthode de Taguchi, Les éditions d'organisation, (1997).

[35] S. Périno-Issartier, C. Ginies, G. Cravotto, F. Chemat, A comparison of essential oils obtained from lavandin via different extraction processes: ultrasound, microwave, turbohydrodistillation, steam and hydrodistillation, J. Chromatogr. A 1305 (2013) 41-47.
[36] S. Shirsath, S. Sonawane, P. Gogate, Intensification of extraction of natural products using ultrasonic irradiations-a review of current status, Chem. Eng. Process. 53 (2012) 10-23.

[37] Y. Kong, Y.-G. Zu, Y.-J. Fu, W. Liu, F.-R. Chang, J. Li, Y.-H. Chen, S. Zhang, C.-B. Gu, Optimization of microwave-assisted extraction of cajaninstilbene acid and pinostrobin from pigeonpea leaves followed by RP-HPLC-DAD determination, J. Food Compos. Anal. 23 (2010) 382-388.

[38] M. Herrera, M. Luque de Castro, Ultrasound-assisted extraction of phenolic compounds from strawberries prior to liquid chromatographic separation and photodiode array ultraviolet detection, J. Chromatogr. A 1100 (2005) 1-7.

[39] M. Pinelo, M. Rubilar, M. Jerez, J. Sineiro, M.J. Núñez, Effect of solvent, temperature, and solvent-to-solid ratio on the total phenolic content and antiradical activity of extracts from different components of grape pomace, J. Agric. Food Chem. 53 (2005) 2111-2117.

[40] J. Prakash Maran, V. Sivakumar, K. Thirugnanasambandham, R. Sridhar, Optimization of microwave assisted extraction of pectin from orange peel, Carbohydr. Polym. 97 (2013) 703-709. 